\title{
An in Vitro Comparison of Bonding Effectiveness of Different Adhesive Strategies on Erbium:Yttrium-Alluminum-Garnet Laser Irradiated Dentin
}

\author{
Daniele Scaminaci Russo' ${ }^{1}$, Jacopo Buti², Luca Giachetti ${ }^{3}$ \\ ${ }^{1}$ Department of Surgery and Translational Medicine, Unit of Dentistry, University of Firenze, Florence, Italy \\ ${ }^{2}$ School of Dentistry, The University of Manchester, Manchester, UK \\ ${ }^{3}$ Department of Surgery and Translational Medicine, Unit of Dentistry, University of Firenze, Florence, Italy \\ Email: luca.giachetti@unifi.it
}

Received 26 October 2015; accepted 16 January 2016; published 19 January 2016

Copyright (C) 2016 by authors and Scientific Research Publishing Inc.

This work is licensed under the Creative Commons Attribution International License (CC BY).

http://creativecommons.org/licenses/by/4.0/

(c) $\underset{\mathrm{BY}}{\mathrm{Br}}$ Open Access

\section{Abstract}

Background: To date there is not a material considered ideal for the lased dentin. Objective: To compare the bond strength to human lased dentin of self-etch and etch-and-rinse adhesive systems, a self-adhesive resin composite and a glass-ionomer cement. Methods: Forty human molars were sectioned to obtain a $2 \mathrm{~mm}$-thick slab of mid-coronal dentin. The occlusal surface of each slab was polished by SiC paper ( $\mathrm{P600}$ ) for $10 \mathrm{~s}$. Then an half part of dentin slabs was randomly selected for receiving treatment with $2.94 \mu \mathrm{m}$ Er:YAG laser (DEKA, Smart 2940D Plus) with $10 \mathrm{~Hz}$ at $100 \mathrm{~mJ}$, pulse duration of $230 \mu \mathrm{s}$ with contact tip. Dentin slabs were randomly divided into four groups $(n=10)$. Six conical frustum-shaped build-ups were constructed on the occlusal surface of each dentin slab using bonding agents (OptiBond Solo Plus Group 1; OptiBond All-in-one Group 2) combined with a resin composite (Premise Flow), self-adhesive resin composites (Vertise Flow Group 3) and a glass-ionomer cement (Ketac-Fil Group 4). Specimens were subjected to $\mu$ SBS test. Data were analyzed by a mixed model and Tukey's test. Results: Measured bond strengths were (mean \pm standard deviation): $20.8 \pm 5.5 \mathrm{MPa}$ (laser treatment) and $15.6 \pm 4.5 \mathrm{MPa}$ (SiC paper) for Group 1, 18.9 \pm 5.3 MPa (laser treatment) and 14.0 \pm 4.3 MPa (SiC paper) for Group 2, 7.9 \pm 2.8 MPa (laser treatment) and 4.3 $\pm 2.2 \mathrm{MPa}$ (SiC paper) for Group 3, 4.7 $\pm 1.9 \mathrm{MPa}$ (laser treatment) and $2.6 \pm 1.2 \mathrm{MPa}$ (SiC paper) for Group 4. The inferential analysis showed that the dentin laser treatment significantly affected the bond strength within each individual group. On dentin treated with laser the bond strengths recorded for build-ups constructed with etch and rinse and self-etch adhesive systems were significantly higher than those recorded for build-ups constructed with 
self-adhesive resin composite and glass-ionomer cement $(p<0.0001)$. Similarly, on dentin treated with $\mathrm{SiC}$ paper the bond strengths recorded for build-ups constructed with etch and rinse and self-etch adhesive systems were significantly higher than those recorded for build-ups constructed with self-adhesive resin composite and glass-ionomer cement $(p<0.0001)$. Conclusion: Er:YAG laser treatment has increased the shear bond strength of all the adhesive materials used.

\section{Keywords}

Adhesion, Micro Shear Bond Strength Test, Dentin, Restorative Materials

\section{Introduction}

The bond strengths to lased tooth substrates reported in the literature are often confusing and even contradictory [1]. Some studies reported higher bond strengths to laser-conditioned dentine than to acid etched dentine [2], while others showed significantly lower bond strengths [3]-[5] or even no significant differences [6]. To date no recommendations have been provided for the use of adhesive systems on irradiated dentin, neither clear consensus has been reached on which material should be considered as the gold standard for this technique [7]. The optimal etching strategy for laser-prepared dentine is controversial too. Different adhesive strategies are currently implemented in modern restorative dentistry including resin composite combined with etch and rinse adhesive systems or self-etch adhesive systems, glass-ionomer cement and self-adhesive resin composite. Many authors investigated the interaction between these systems and lased dentin. For the etch and rinse system, Er:YAG laser ablation creates a smear layer free dentin surface, but is not able to expose any dentin collagen fibres [8], that are required to the formation of hybrid layer. However, Er:YAG laser irradiation produces a laser-modified superficial layer with a peculiar morphological pattern in which collagen fibres are partially denatured, fused and/or melted, poorly attached to the underlying dentine substrate and have lost part of their cross-banding [9]. This amorphous collagen layer is completely devoid of interfibrillar spaces and probably restricts resin diffusion into the subsurface intertubular dentine, thus undermining the formation of an authentic, typical hybrid layer [9].

For self-etch adhesive system a decrease in bond strength to lased dentin was also demonstrated [10]. The poor efficacy of self-etching primers on laser-treated dentine could be attributed to the limited capacity of the acidic monomer to demineralize the laser-modified superficial layer and alter the resulting morphological pattern. According to previous studies [11], the degradation of organic dentine and the changes in size and ultrastructure of apatite crystals due to laser irradiation substantially increase the acid-resistance of lased dentine. Additionally, it has been reported [12] [13] that Er:YAG laser irradiation reduces the carbon-to phosphorus ratio and leads to the formation of more stable and less acid-soluble compounds, thus reducing the susceptibility of dentine to acid attack. Therefore, it seems feasible that an etchant agent with stronger acid potential, such as 35\% phosphoric acid, would remove the laser-modified dentine layer more efficiently than an etchant agent with weaker acid potential, such as the acidic monomer in self-etching primers. However, many other studies have also found self-etch adhesives to be more effective than etch and rinse adhesives for dentine-ablated specimens [14]-[17].

Glass-ionomer cements self-adhere to tooth tissue through combined micromechanical and chemical bonding. The Er:YAG laser creates a rough microretentive pattern that has the potential to aid retention of these materials. Unfortunately the determination of tensile bond strength with conventional glass-ionomer cements is not straightforward, as these are brittle materials and failure during testing occurs frequently within the cement [18]. The investigation of bond strength was limited to resin modified glass-ionomer cements and the information is insufficient to draw conclusions. No information is currently available on the effects of Er:YAG-lased tooth substance on the bond strength of conventionally-setting glass-ionomer cement and therefore they are not enough to provide significant insights [7].

Recently, new self-adhering flowable resin composite has been developed. According to the manufacturers, this resin bonds to tooth substrate without the use of adhesive system due to their acidic monomer composition. Ruya Yazici et al. evaluated the shear bond strength of a self-adhesive flowable resin (Vertise; Kerr, Orange, CA, US) to dentin prepared with bur or with Er:YAG laser. Vertise flow showed significantly higher bond 
strength values to laser prepared surfaces than bur prepared surfaces. The authors claim that the lased dentin morphology provides a significant advantage to the adhesion of Vertise. They suppose that the opened dentinal tubules allow the resin infiltration and the resin tags formation. Moreover the smear layer free surface enhances the chemical bonding of the material [19]. Due to the preliminary nature of those presented studies more specific investigation is needed.

The aim of this in-vitro study is to compare the bond strength of an etch and rinse and a self-etch adhesive system combined with a resin composite, a self-adhesive resin composite and a glass-ionomer cement to laser and silicon carbide $(\mathrm{SiC})$ paper-prepared human dentin by means of micro shear bond strength ( $\mu \mathrm{SBS}$ ) test.

The three hypotheses tested were: 1 ) there is no difference between the bond strength of the tested materials applied on dentin treated with laser and that of the tested materials applied on dentin treated with SiC paper; 2) there is no difference between the bond strength of tested materials applied on dentin treated with laser; 3) there is no difference between the bond strength of tested materials applied on dentin treated with $\mathrm{SiC}$ paper.

\section{Materials and Methods}

In this study the micro shear bond strength test was performed following the same procedure described in previous published studies [20] [21].

\subsection{Specimen Preparation for the Micro Shear Bond Strength Test}

Forty caries-free human molars extracted for periodontal disease, which were stored in distilled water (grade 3) at $4^{\circ} \mathrm{C}$ for less than 3 months after extraction, were debrided of excess tissue, residual plaque and calculus with an ultrasonic scaler (Minipiezon, EMS, Milano, Italy) and Gracey curettes (Hu-Friedy Mfg. Co., Chicago, IL, USA).

The enamel surface of each tooth was etched with 37.5\% phosphoric acid gel (Gel Etchant, Kerr, Orange, CA, US) for 30 seconds, rinsed with water and air-dried. A layer of unfilled resin was applied to the conditioned enamel (Heliobond, Ivoclar Vivadent, Schaan, Liechtenstein.) and light-polymerized for 10 seconds (Astralis 10, High Power Program $1200 \mathrm{~mW} / \mathrm{cm}^{2}$, Vivadent-Ivoclar). The aim of this procedure was to obtain a reliable bond between the tooth surface and the acrylic resin in which each tooth was subsequently embedded by using a steel mold leaving the occlusal surface of the crown exposed. Each encased tooth was sectioned perpendicularly to its long axis at the middle third of the crown, using a water-cooled low-speed diamond saw (Micromet, Remet, Bologna, Italy) to remove the occlusal enamel portion, which was discarded. The acrylic blocks were transversally sectioned again to obtain a 2 mm-thick slab of mid-coronal dentin framed by acrylic resin. A hole in the acrylic resin was made perpendicularly to the section surface using a hand piece and a parallel meter (CL-MF2002S, Heraeus-Kulzer Inc, Hanau, Germany) in order to allow the correct and repeatable placement of the slab during the mechanical test. The occlusal surface of each slab was polished by P600 grit silicon carbide abrasive paper (WS Flex 18 C, Hermes Abrasives Ltd, Virginia Beach, VA, USA) under running water using a lapping machine (LS2, Remet) for $10 \mathrm{~s}$ to create a homogenous smear layer on the dentin. During preparation the specimens were kept moist by immersion in distilled water (grade 3) at $23^{\circ} \mathrm{C} \pm 2^{\circ} \mathrm{C}$.

Each dentin slab was rinsed with water and gently air-dried. Then an half part of dentin slab was randomly selected for receiving treatment with Er:YAg laser while on the other half part no laser treatment was performed and the surface maintains the characteristics obtained by SiC-paper abrasion. The marked areas were then irradiated with the Er:YAG laser (DEKA, Smart 2940D Plus, Firenze, Italy) with a wavelength of $2.94 \mu \mathrm{m}$ and a contact tip with a repetition rate of $10 \mathrm{~Hz} / 100 \mathrm{~mJ}(1 \mathrm{~W})$ and pulse duration of $230 \mu$ s under water cooling spray (water pressure level maximum). The laser beam spot size was $1 \mathrm{~mm}$ and was moved by hand in a sweeping fashion. The laser exposure time was 40 seconds for each specimen. The irradiated dentin area was approximately $10 \mathrm{~mm}^{2}$ for each specimen.

Dentin slabs were randomly divided into four groups $(\mathrm{n}=10)$ according to restorative material employed:

- Group 1: two-step etch and rinse adhesive system (Optibond Solo Plus, Kerr) combined with a resin composite (Premise Flow, Kerr)

- Group 2: one-step self-etch system (OptiBond All-in-One, Kerr) combined with a resin composite (Premise Flow, Kerr)

- Group 3: self-adhering light curing resin composite (Vertise Flow, Kerr)

- Group 4: glass-ionomer cement (Ketac-Fil Plus, 3M ESPE, St. Paul, MN, US). 
In Group 1, the occlusal surface of each dentin slab was treated with 37.5\% phosphoric acid (Gel Etchant; Kerr) for $10 \mathrm{sec}$, rinsed and gently air-dried and then was treated with the adhesive system according to manufacturer's instructions except for the light-activation that was not performed [22]. In Group 2, the occlusal surface of each dentin slab was treated with adhesive system according to manufacturer's instructions except for the light-activation that was not performed [20]. In Group 3 no surface treatment was performed. In Group 4, the occlusal surface of each dentin slab was treated with poliacrylic acid (Ketac Conditioner, 3M ESPE) for 10 sec, then was rinsed and gently air-dried according to manufacturer's instructions.

The build-ups were constructed using a custom made device (Figure 1) consisting of two, 1 mm-thick metal plates and two, 1 mm-thick flexible silicon sheets, which could be joined by means of four screws. Both metal plates had 6 holes (1.5 mm diameter). One silicon sheet was perforated using a rubber dam punch instrument (Ivory 57225, Ivory Dental, Plainfield, IL, USA) thus obtaining 6 conical frustum-shaped holes (larger diameter $=1.45 \mathrm{~mm}$; smaller diameter $=0.95 \mathrm{~mm}$ ). The position, size and shape of the holes were standardized by using the metal plate of the custom made device instead of the rotating cutting disc of the punch instrument.

Each dentin slab was placed into the device, which was assembled according to the following steps. A perforated silicon sheet was placed on the occlusal surface of the dentin slab. The conical frustum-shaped holes on the silicon sheet were then filled with restorative material. The restorative materials were applied into the holes by means of the provided tip. In addition, according to the manufacturer, the self-adhesive light-curing resin composite was scrubbed for 20s using the provided brush that has been specially modified to make it smaller so that it can enter the hole of the silicon sheet. Subsequently, a non-perforated silicon sheet was placed on the perforated sheet and finally the metal plate was positioned on top so that its holes were perfectly aligned with those of the silicon sheet. The components of the device were then joined together with the four screws. In Groups 1,2 and 3 the resin composite was subsequently light cured (Astralis 10, High Power Program 1200 mW/cm², Vivadent-Ivoclar) through the holes in the metal plate for $20 \mathrm{~s}$. After opening the device, the silicon sheets could be easily removed from the build ups. The build-ups of Group 4, which were realized with glass-ionomer cement, were not light-activated, therefore the device was opened after an elapse of 10 minutes, according to setting time indicated by manufacturer.

This procedure was performed at $23^{\circ} \mathrm{C} \pm 2{ }^{\circ} \mathrm{C}$ and $50 \% \pm 5 \%$ relative humidity. After opening the device, the silicon sheets could be easily removed from the build ups. As a result, up to a maximum of 6 aligned conical frustum-shaped build-ups, whose smaller base was bonded to the dentin surface, were constructed on the occlusal surface of each dentin slab by a single operator with lab experience. Three build-ups were located on lased dentin while the other three were located on silicon carbide (SiC) paper-prepared dentin.

The specimens were stored in water in a light-proof container at $37^{\circ} \mathrm{C}$ for $24 \mathrm{~h}$ and then were observed at the stereomicroscope (4× magnification) (SMZ-10, Nikon Corporation, Tokyo, Japan) in order to verify integrity at the resin-dentin interface. Build-ups that showed apparent interfacial gap formation, bubble inclusion, or any other relevant defects were excluded from the study.

Specimens were subjected to micro shear bond strength test using a mechanical testing machine (LMT-100, LAM Technologies). Both jigs of the testing machine had one pin. Dentin slabs were positioned onto the moving jig so that pin passed through one of the holes previously made in the acrylic resin frame. A thin steel wire $(\varnothing=0.23 \mathrm{~mm}$ ) (Leone S.p.a., Firenze, Italy) was looped around the pin of the other jig and around each resin build-up, making contact through half its circumference. The geometric shape of build-ups (inverted conical frustum) allowed the wire to be gently held flush against the dentin at the resin/dentin interface throughout the test. The dentine slab could freely rotate around the pin. Consequently, the composite build-up and the centre of the load cell were in perfect alignment whereas the wire loop was kept parallel to the load cell movement direction and to the bonded surface in order to maintain stress orientation as shear at the bonding interface (Figure 2). Shear force was applied to the resin/dentin interface at a crosshead speed of $1 \mathrm{~mm} / \mathrm{min}$ until failure occurred. This procedure was performed at $23^{\circ} \mathrm{C} \pm 2{ }^{\circ} \mathrm{C}$ and $50 \% \pm 5 \%$ relative humidity. The $\mu$ SBS was expressed in $\mathrm{MPa}$, as derived from dividing the imposed force $(\mathrm{N})$ at the time of fracture by the bond area $\left(0.71 \mathrm{~mm}^{2}\right)$.

\subsection{Statistical Analysis}

Statistical analysis consists of a preliminary descriptive of variables, premature failure (absolute and relative frequency) and strength (mean, standard deviation, range and median). Between-group and between-treatment 


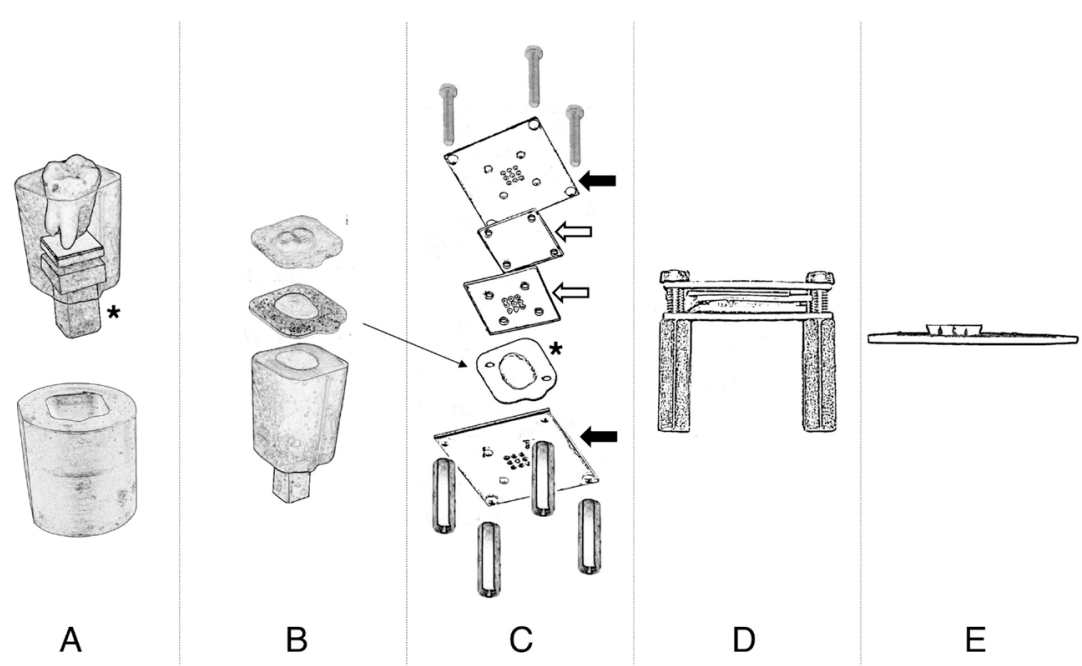

Figure 1. Specimen preparation. (A) Each tooth was encased in acrylic resin inside a steel mold. A square section metal pin (asterisk) was inserted at the bottom end of the acrylic resin block to facilitate the positioning of samples onto the precision sectioning saw. (B) Each tooth was sectioned perpendicularly to its long axis, a first time in order to remove the occlusal enamel, and a second time, to obtain a $2 \mathrm{~mm}$-thick slab of mid-coronal dentin framed by acrylic resin. (C) Metal device for specimen construction. Each dentin slab-framed by acrylic resin (asterisk) — was placed between the 2 metal plates (full arrow) and the silicon sheets (blank arrow), which were then joined together with 4 screws. (D) Assembled custom made device. (E) Six perfectly aligned conical frustum-shaped build-ups, whose smaller base was bonded to the dentin surface, were constructed on both surfaces of each dentin slab.
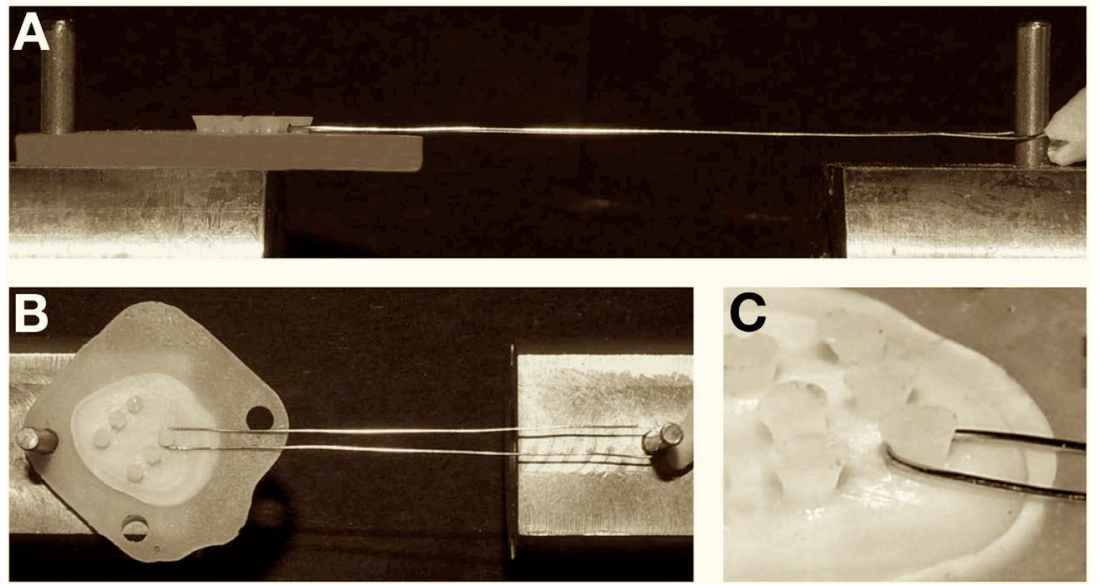

Figure 2. Mechanical testing machine. (A) The dentin-resin interface, the wire loop and the centre of the load cell were aligned, thus allowing the application of the shear force; (B) The hole in the acrylic resin ensured the automatic alignment of the slabs during the mechanical test; (C) The geometric shape of build-ups (inverted conical frustum) allowed the wire to be gently held flush against the dentin at the resin/dentin interface throughout the test.

modality differences in the bond strength were statistically assessed using a mixed model where bond strength represented the outcome variable. The variables "Group" and "Treatment" were used as fixed effects while the variable "tooth" was used as random effect. Interactions between "Group" and "Treatment” were also analysed. Tukey's test was successfully applied for post hoc comparison. In all the analyses the level of significance was set at $\mathrm{p}<0.05$ (JMP, Version 9.0, SAS Institute Inc., Cary, NC, USA). 


\section{Results}

The results of the statistic model are shown in Tables 1-5. This study involved the preparation of 6 build-ups on each substrate. Out of 240 build-ups, 43 either prematurely failed or accidentally detached from their base after opening the device (Table 1). As a result, a total of 197 build-ups were subjected to mechanical test.

Table 1. Results.

\begin{tabular}{|c|c|c|c|c|}
\hline Group & $\begin{array}{c}\text { Laser } \\
\text { treatment }\end{array}$ & $\begin{array}{l}\text { Accidentally detached after } \\
\text { opening the device }\end{array}$ & $\begin{array}{l}\text { Subjected to } \\
\text { mechanical test }\end{array}$ & $\begin{array}{l}\mu S B S \text { test result } \\
\text { (MPa) }\end{array}$ \\
\hline \multirow{2}{*}{ 1. OptiBond solo plus } & yes & 0 & 30 & $20.8 \pm 5.5$ \\
\hline & no & 6 & 24 & $15.6 \pm 4.5$ \\
\hline \multirow{2}{*}{ 2. Optibond All-in-one } & yes & 3 & 27 & $18.9 \pm 5.3$ \\
\hline & no & 4 & 26 & $14.0 \pm 4.3$ \\
\hline \multirow{2}{*}{ 3. Vertise Flow } & yes & 15 & 15 & $7.9 \pm 2.8$ \\
\hline & no & 12 & 18 & $4.3 \pm 2.2$ \\
\hline \multirow{2}{*}{ 4. ketac fil } & yes & 1 & 29 & $4.7 \pm 1.9$ \\
\hline & no & 2 & 28 & $2.6 \pm 1.2$ \\
\hline Total & & 43 & 197 & \\
\hline
\end{tabular}

Descriptive statistics of micro-shear bond strength test.

Table 2. Results of mixed models analysis: Laser vs SiC within-group differences.

\begin{tabular}{ccccccc}
\hline & $\begin{array}{c}\text { Laser } \\
\text { LS Mean }\end{array}$ & $\begin{array}{c}\text { SiC } \\
\text { LS Mean }\end{array}$ & $\begin{array}{c}\text { LS } \\
\text { Mean Diff. }\end{array}$ & $\begin{array}{c}\text { LS } \\
\text { SE }\end{array}$ & 95\% CI & p-value \\
\hline Group 1 & 20.78 & 15.62 & 5.17 & 1.39 & $2.37 ; 7.96$ & $0.0005^{*}$ \\
Group 2 & 18.93 & 13.99 & 4.94 & 1.24 & $2.46 ; 7.42$ & $0.0002^{*}$ \\
Group 3 & 7.94 & 4.32 & 3.62 & 0.69 & $2.25 ; 5.00$ & $<0.0001^{*}$ \\
Group 4 & 4.78 & 2.52 & 2.26 & 0.55 & $1.13 ; 3.39$ & $0.0003^{*}$ \\
\hline
\end{tabular}

*Statistically significant between-treatment differences $(\mathrm{p}<0.05)$. LS = Least Squares. SE = Standard Error.

Table 3. Effects of laser treatment on the bond strength of the tested materials.

\begin{tabular}{|c|c|c|c|c|c|}
\hline \multirow{2}{*}{$\begin{array}{c}\text { Groups Comparison } \\
1 \text { vs } 4\end{array}$} & \multirow{2}{*}{$\begin{array}{c}\text { LS Means Diff. } \\
15.85\end{array}$} & \multirow{2}{*}{$\begin{array}{c}\text { LS SE } \\
1.41\end{array}$} & \multicolumn{2}{|c|}{$95 \%$ CI } & \multirow{2}{*}{$\begin{array}{l}\text { p-value } \\
<0.0001^{*}\end{array}$} \\
\hline & & & 12.16 & 19.53 & \\
\hline Groups & LS Mean & & & & \\
\hline $1^{\mathrm{a}}$ & 20.72 & & & & \\
\hline $2^{\mathrm{a}}$ & 18.91 & & & & \\
\hline $3^{\mathrm{b}}$ & 7.93 & & & & \\
\hline $4^{\mathrm{b}}$ & 4.87 & & & & \\
\hline 2 vs 4 & 14.04 & 1.38 & 10.42 & 17.65 & $<0.0001^{*}$ \\
\hline 1 vs 3 & 12.79 & 1.15 & 9.79 & 15.79 & $<0.0001^{*}$ \\
\hline 2 vs 3 & 10.98 & 1.13 & 8.04 & 13.92 & $<0.0001^{*}$ \\
\hline 3 vs 4 & 3.06 & 1.38 & -0.54 & 6.66 & 0.1254 \\
\hline 1 vs 2 & 1.81 & 1.16 & -1.22 & 4.84 & 0.4048 \\
\hline
\end{tabular}

In the Groups column different bold letters label statistically significant between-group differences $(p<0.05)$. ${ }^{*}$ statistically significant betweentreatment differences $(\mathrm{p}<0.05)$. LS = Least Squares. SE = Standard Error. 
Table 4. Effects of SiC Paper treatment on the bond strength of the tested materials.

\begin{tabular}{|c|c|c|c|c|c|}
\hline \multirow{2}{*}{$\begin{array}{c}\text { Groups Comparison } \\
1 \text { vs } 4\end{array}$} & \multirow{2}{*}{$\begin{array}{c}\text { LS Means Diff. } \\
13.05\end{array}$} & \multirow{2}{*}{$\begin{array}{c}\text { LS SE } \\
1.08\end{array}$} & \multicolumn{2}{|c|}{$95 \%$ CI } & \multirow{2}{*}{$\begin{array}{l}\text { p-value } \\
<0.0001^{*}\end{array}$} \\
\hline & & & 10.23 & 15.87 & \\
\hline Groups & LS Mean & & & & \\
\hline $1^{\mathrm{a}}$ & 15.62 & & & & \\
\hline $2^{\mathrm{a}}$ & 14.03 & & & & \\
\hline $3^{\mathrm{b}}$ & 4.32 & & & & \\
\hline $4^{\mathrm{b}}$ & 2.57 & & & & \\
\hline 2 vs 4 & 11.46 & 1.06 & 8.68 & 14.24 & $<0.0001^{*}$ \\
\hline 1 vs 3 & 11.30 & 0.99 & 8.70 & 13.90 & $<0.0001^{*}$ \\
\hline 2 vs 3 & 9.71 & 0.98 & 7.15 & 12.27 & $<0.0001^{*}$ \\
\hline 3 vs 4 & 1.75 & 1.10 & -1.12 & 4.62 & 0.3849 \\
\hline 1 vs 2 & 1.59 & 0.96 & -0.91 & 4.09 & 0.3494 \\
\hline
\end{tabular}

In the Groups column different bold letters label statistically significant between-group differences $(\mathrm{p}<0.05)$. * statistically significant betweentreatment differences $(\mathrm{p}<0.05)$. LS = Least Squares. SE = Standard Error.

\section{Analysis of Resistance at Break}

1) Laser treatment vs. SiC Paper

Measured bond strengths were (mean \pm standard deviation): $20.8 \pm 5.5 \mathrm{MPa}$ (laser treatment) and $15.6 \pm 4.5$ $\mathrm{MPa}$ (SiC paper) for Group 1, 18.9 $\pm 5.3 \mathrm{MPa}$ (laser treatment) and 14.0 $\pm 4.3 \mathrm{MPa}$ (SiC paper) for Group 2, 7.9 $\pm 2.8 \mathrm{MPa}$ (laser treatment) and 4.3 $\pm 2.2 \mathrm{MPa}$ (SiC paper) for Group 3, 4.7 $\pm 1.9 \mathrm{MPa}$ (laser treatment) and 2.6 $\pm 1.2 \mathrm{MPa}$ (SiC paper) for Group 4 (Table 2). The inferential analysis showed that the dentin laser treatment significantly affected the bond strength within each individual group. In particular, statistically significant differences (mean \pm standard error) of $5.17 \pm 1.39$ ( $\mathrm{p}=0.0005), 4.94 \pm 1.24(\mathrm{p}=0.0002), 3.62 \pm 0.69(\mathrm{p}<0.0001)$ and $2.26 \pm 0.55$ ( $\mathrm{p}=0.0003$ ) were estimated in favour of laser treatment for build-ups constructed with etch and rinse (Group 1) and self-etch (Group 2) adhesive systems, with self-adhesive resin composite (Group 3) and with glass-ionomer cement (Group 4), respectively (Table 2).

2) Laser Treatment

On dentin treated with laser the bond strengths recorded for build-ups constructed with etch and rinse and self-etch adhesive systems were significantly higher than those recorded for build-ups constructed with self-adhesive resin composite and glass-ionomer cement $(\mathrm{p}<0.0001)$. All pair-wise differences are reported in Table 3.

3) $\mathrm{SiC}$ Paper Treatment

Similarly, on dentin treated with SiC paper the bond strengths recorded for build-ups constructed with etch and rinse and self-etch adhesive systems were significantly higher than those recorded for build-ups constructed with self-adhesive resin composite and glass-ionomer cement $(p<0.0001)$. All pair-wise differences are reported in Table 4.

4) Interactions between type of dentin treatment and type of tested material

Mixed models analysis allowed testing the interactions between "Group" and "Treatment" in order to estimate all potential pair-wise comparisons of different combinations of the type of treatment dentin with the type of material tested. Results of the model showed that the bond strengths recorded for build-ups constructed with etch and rinse and self-etch adhesive systems combined with resin composite on dentin treated with laser are statistically significant higher than those recorded in all other groups ( $\mathrm{p}<0.0001)$ (Table 5).

\section{Discussion}

Several studies evaluated the bond strength of etch and rinse and self-etch adhesives systems to dentin treated with laser. Conversely, literature does not show enough information regarding the performance of the self-adhesive resin composites and glass-ionomer cement applied on dentin treated with laser. Moreover, it is difficult 
Table 5. Effects of the type of treatment dentin with the type of material tested.

\begin{tabular}{|c|c|c|c|c|c|}
\hline \multicolumn{2}{|c|}{ Comparison } & \multirow{2}{*}{$\begin{array}{c}\text { LS } \\
\text { Mean Diff. }\end{array}$} & \multirow{2}{*}{$\begin{array}{l}\text { LS } \\
\text { SE }\end{array}$} & \multirow{2}{*}{$95 \%$ CI } & \multirow{2}{*}{ p-value } \\
\hline Group, Treatment & Group, Treatment & & & & \\
\hline 1, laser & 4, SiC & 18.21 & 1.20 & $14.52 ; 21.89$ & $<0.0001^{*}$ \\
\hline 2, laser & 4, SiC & 16.38 & 1.19 & $12.74 ; 20.01$ & $<0.0001^{*}$ \\
\hline Groups & LS means & & & & \\
\hline 1 laser $^{\mathrm{a}}$ & 20.73 & & & & \\
\hline 2 laser $^{\mathrm{a}}$ & 18.90 & & & & \\
\hline $1 \mathrm{SiC}^{\mathrm{b}}$ & 15.59 & & & & \\
\hline $2 \mathrm{SiC}^{\mathrm{b}}$ & 14.00 & & & & \\
\hline 3 laser $^{c}$ & 7.93 & & & & \\
\hline 4 laser $^{\mathrm{cd}}$ & 4.83 & & & & \\
\hline $3 \mathrm{SiC}^{\mathrm{d}}$ & 4.40 & & & & \\
\hline $4 \mathrm{SiC}^{\mathrm{d}}$ & 2.53 & & & & \\
\hline 1 , laser & 3, SiC & 16.33 & 1.12 & $12.91 ; 19.75$ & $<0.0001^{*}$ \\
\hline 1 , laser & 4, laser & 15.91 & 1.28 & $11.97 ; 19.83$ & $<0.0001^{*}$ \\
\hline 2, laser & 3, SiC & 14.50 & 1.09 & $11.15 ; 17.85$ & $<0.0001^{*}$ \\
\hline 2 , laser & 4, laser & 14.08 & 1.26 & $10.21 ; 17.94$ & $<0.0001^{*}$ \\
\hline $1, \mathrm{SiC}$ & 4, SiC & 13.06 & 1.21 & $9.34 ; 16.78$ & $<0.0001^{*}$ \\
\hline 1 , laser & 3 , laser & 12.80 & 1.05 & $9.58 ; 16.02$ & $<0.0001^{*}$ \\
\hline 2, $\mathrm{SiC}$ & 4, $\mathrm{SiC}$ & 11.48 & 1.19 & 7.82; 15.14 & $<0.0001^{*}$ \\
\hline $1, \mathrm{SiC}$ & 3, $\mathrm{SiC}$ & 11.19 & 1.12 & $7.74 ; 14.63$ & $<0.0001^{*}$ \\
\hline 2, laser & 3 , laser & 10.98 & 1.03 & 7.82; 14.13 & $<0.0001^{*}$ \\
\hline $1, \mathrm{SiC}$ & 4, laser & 10.76 & 1.29 & $6.82 ; 14.71$ & $<0.0001^{*}$ \\
\hline 2, $\mathrm{SiC}$ & 3, SiC & 9.60 & 1.10 & $6.22 ; 12.99$ & $<0.0001^{*}$ \\
\hline 2, $\mathrm{SiC}$ & 4, laser & 9.18 & 1.27 & $5.28 ; 13.07$ & $<0.0001^{*}$ \\
\hline $1, \mathrm{SiC}$ & 3 , laser & 7.66 & 1.06 & $4.42 ; 10.90$ & $<0.0001^{*}$ \\
\hline 1 , laser & 2, $\mathrm{SiC}$ & 6.73 & 1.07 & $3.46 ; 10.00$ & $<0.0001^{*}$ \\
\hline 2, $\mathrm{SiC}$ & 3 , laser & 6.08 & 1.04 & $2.89 ; 9.25$ & $<0.0001^{*}$ \\
\hline 3 , laser & 4, $\mathrm{SiC}$ & 5.40 & 1.18 & $1.79 ; 9.01$ & $0.0002^{*}$ \\
\hline 1 , laser & $1, \mathrm{SiC}$ & 5.14 & 1.09 & $1.82 ; 8.47$ & $0.0001^{*}$ \\
\hline 2, laser & 2, $\mathrm{SiC}$ & 4.90 & 1.05 & $1.69 ; 8.11$ & $0.0001^{*}$ \\
\hline 3 , laser & 3, SiC & 3.53 & 1.09 & $0.20 ; 6.86$ & $0.0293^{*}$ \\
\hline 2, laser & $1, \mathrm{SiC}$ & 3.32 & 1.07 & $0.04 ; 6.59$ & $0.0445^{*}$ \\
\hline 3 , laser & 4, laser & 3.10 & 1.25 & $-0.74 ; 6.95$ & 0.2137 \\
\hline 4, laser & 4, SiC & 2.30 & 1.39 & $-1.95 ; 6.56$ & 0.7142 \\
\hline 3, $\mathrm{SiC}$ & 4, $\mathrm{SiC}$ & 1.87 & 1.24 & $-1.92 ; 5.67$ & 0.7989 \\
\hline 1 , laser & 2, laser & 1.83 & 1.06 & $-1.41 ; 5.07$ & 0.6680 \\
\hline 1, SiC & 2, SiC & 1.58 & 1.08 & $-1.71 ; 4.88$ & 0.8210 \\
\hline 4, laser & 3, SiC & 0.43 & 1.30 & $-3.56 ; 4.41$ & 1.0000 \\
\hline
\end{tabular}

In the Groups column different bold letters label statistically significant between-group differences $(\mathrm{p}<0.05)$. ${ }^{*}$ statistically significant betweentreatment differences $(\mathrm{p}<0.05)$. LS = Least Squares. SE $=$ Standard Error. 
to draw strong conclusions from the data reported in the literature due to the limited number of studies conducted under comparable conditions, i.e. using the same cements, substrates, curing and storage conditions. Therefore, the present study was designed to simultaneously compare the bond strength of an etch and rinse and a self-etch adhesive system combined with a resin composite, a self-adhesive resin composite and a glassionomer cement to laser and silicon carbide (SiC) paper-prepared human dentin.

The results of this study showed that all the tested materials performed better in terms of bond strength when applied on laser treated dentin than when applied on dentin treated with SiC paper. Moreover, the etch and rinse and the self-etch adhesive systems exhibited significant higher bond strengths than those shown by the self-adhesive resin cement and the glass-ionomer cement both when applied on laser treated dentin and on dentin treated with $\mathrm{SiC}$ paper.

Different methods are available to perform in-vitro analysis of bond strength to tooth surfaces. The microtensile bond strength test was used in most of the above mentioned studies. However, it has been demonstrated that micro-tensile bond strength measurements are relevantly affected by the mechanical properties of the overlaid restorative composite [23] [24]. In this study, the micro-shear bond strength test was then chosen in order to compares materials with different mechanical properties. The micro-tensile technique is extremely sensitive and, when materials or substrates with relatively low bond strength values are tested, specimens tend to fail prematurely during preparation [25]. In addition, the tensile bond strength of conventional glass-ionomers is not easily estimated as these materials are brittle and characterized by frequent occurrence of failure within the cement during testing [18]. Beside, greater the bond strength values, higher the chance of cohesive failures with fractures in dentin due to a non-uniform load distribution [25]. The assumption that comparing different materials within the same study is viable by using the micro-shear bond strength test was confirmed in a previous study [20].

In addition, the micro-shear bond strength test requires a method of preparation of the specimens able to eliminate the variable substrate. Therefore, each dentin slab received both treatments (laser and SiC paper) in order to perform the test on the same substrate.

A common finding in present-day studies dealing with the tooth/adhesive material interface was the recommendation of using lower energy outputs for cavity preparation than in the past. In order to obtain a more retentive surface without cohesive microfractures, it would be advisable to apply an energy output inferior to or around $200 \mathrm{~mJ}$ for dentin and enamel using the Er:YAG laser [26].

In this study the energy applied to the specimens was probably sufficient to obtain a rough surface that could contribute to the adhesion of resin to dentin without producing the presence of fragments and microfractures. The latter were reported to negatively affect the adhesion of resin reducing the bonding quality [27].

The results of this study showed that all the tested materials performed better in terms of bond strength when applied on laser treated dentin than when applied on dentin treated with SiC paper. However, the laser treatment resulted in an increase of the bond strength higher for self-adhesive resin composite and glass-ionomer cement than the adhesive systems. Unlike adhesives that make a micro-mechanical interlocking with collagen fibres, self-adhesive resin composites and glass-ionomer cements employ mainly chemical adhesion. It is well know that laser treatment causes an increase in the surface roughness. Therefore, the irregular and microretentive surface of Er:YAG-lased dentin showed to improve performance of chemical-adhesive materials such as self-adhesive resin composite and glass-ionomer cement compared to mechanical-adhesive materials. Consequently Er:YAG laser treatment could be effectively used to improve the performance of self-adhesive materials employed in the cementation of fixed prosthodontics and as filling materials.

\section{Conclusion}

In conclusion, the Er:YAG laser treatment employed in this study has increased the shear bond strength of all the adhesive materials used. Leveraging on the results of this study, further studies are recommended with a view to establishing a reliable procedure for bond adhesive restorative materials to Er:YAG laser ablated dentin. These studies should include examining the dentin adhesive materials interfaces by means of microscopic and microleakage analysis. Clinical studies should be conducted.

\section{Disclosure Statement}

No competing financial interests exist. 


\section{References}

[1] Lopes, R.M., Trevelin, L.T., da Cunha, S.R., de Oliveira, R.F., de Andrade Salgado, D.M., de Freitas, P.M., de Paula Eduardo, C. and Aranha, A.C. (2015) Dental Adhesion to Erbium-Lased Tooth Structure: A Review of the Literature. Photomedicine and Laser Surgery, 33, 393-403. http://dx.doi.org/10.1089/pho.2015.3892

[2] Visuri, S.R., Gilbert, J.L., Wright, D.D., Wigdor, H.A. and Walsh Jr., J.T. (1996) Shear Strength of Composite Bonded to Er:YAG Laser-Prepared Dentin. Journal of Dental Research, 75, 599-605. http://dx.doi.org/10.1177/00220345960750011401

[3] Armengol, V., Laboux, O., Weiss, P., Jean, A. and Hamel, H. (2003) Effects of Er:YAG and Nd:YAP Laser Irradiation on the Surface Roughness and Free Surface Energy of Enamel and Dentin: An in Vitro Study. Operative Dentistry, 28, 67-74.

[4] Farrar, S.R., Attril, D.C., Dickinson, M.R., King, T.A. and Blinkhorn, A.S. (1997) Etch Rate and Spectroscopic Ablation Studies of Er:YAG Laser Irradiated Dentine. Applied Optics, 36, 5641-5646. http://dx.doi.org/10.1364/AO.36.005641

[5] Kameyama A, Kawada E, Takizawa M, Oda Y, Hirai Y. (200) Influence of Different Acid Conditioners on the Tensile Bond Strength of 4-META/MMA-TBB Resin to Er:YAG Laser-Irradiated Bovine Dentin. Journal of Adhesive Dentistry, 2, 297-304.

[6] Nakajima, M., Sano, H., Burrow, M.F., Tagami, J., Yoshiyama, M., Ebisu, S., Ciucchi, B., Russell, C.M. and Pashley, D.H. (1995) Tensile Bond Strength and SEM Evaluation of Caries-Affected Dentin Using Dentin Adhesives. Journal of Dental Research, 74, 1679-1688. http://dx.doi.org/10.1177/00220345950740100901

[7] de Moor, R.J.G. and Delmè, K.I.M. (2010) Laser-Assisted Cavity Preparation and Adhesion to Erbium-Lased Tooth Structure: Part 2. Present Day Adhesion to Erbium Lased Tooth Structure in Permanent Teeth. Journal of Adhesive Dentistry, 12, 91-102.

[8] Kataumi, M., Nakajima, M., Yamada, T. and Tagami, J. (1998) Tensile Bond Strength and SEM Evaluation of Er:YAG Laser Irradiated Dentin using Dentin Adhesive. Dental Material Journal, 17, 125-138. http://dx.doi.org/10.4012/dmj.17.125

[9] Ceballos, L., Toledano, M., Osorio, R., Tay, F.R. and Marshall, G.W. (2002) Bonding to Er-YAG Laser Treated Dentine. Journal of Dental Research, 81, 119-122. http://dx.doi.org/10.1177/154405910208100207

[10] de Oliveira, M.T., Reis, A.F., Arrais, C.A., Cavalcanti, A.N., Aranha, A.C., de Paula Eduardo, C. and Giannini, M. (2013) Analysis of the Interfacial Micromorphology and Bond Strength of Adhesive Systems to Er:YAG Laser Irradiated Dentin. Lasers in Medical Science, 28, 1069-1076. http://dx.doi.org/10.1007/s10103-012-1157-5

[11] Arimoto, N., Suzaki, A., Sakuma, K., Kashihara, S., Yamada, M. and Senda, A. (1999) Micro Structural Changes in Dentine Irradiated Er:YAG Laser. Journal of Dental Research, 78, 316.

[12] Hossain, M., Nakamura, Y., Kimura, Y., Yamada, Y., Ito, M. and Matsumoto, K. (2000) Caries-Preventive Effect of Er:YAG Laser Irradiation with or without Water Mist. Journal of Clinical Laser Medicine and Surgery, 18, 61-65.

[13] Contreras-Arriaga, B., Rodríguez-Vilchis, L.E., Contreras-Bulnes, R., Olea-Mejìa, O.F., Scougall-Vilchis, R.J. and Centeno-Pedraza, C. (2015) Chemical and Morphological Changes in Human Dentin after Er:YAG Laser Irradiation: EDS and SEM Analysis. Microscopy Research and Technique, 78, 1019-1025. http://dx.doi.org/10.1002/jemt.22579

[14] Van Meerbeek, B., De Munck, J., Mattar, D., Van Landuyt, K. and Lambrechts, P. (2003) Microtensile Bond Strengths of an Etch-and-Rinse and Self-Etch Adhesive to Enamel and Dentine as a Function of Surface Treatment. Operative Dentistry, 28, 647-660.

[15] Hossain, M., Yamada, Y., Nakamura, Y., Murakami, Y., Tamaki, Y. and Matsumoto, K. (2003) A Study on Surface Roughness and Microleakage Test in Cavities Prepared by Er:YAG Laser Irradiation and Etched Bur Cavities. Lasers in Medical Science, 18, 25-31. http://dx.doi.org/10.1007/s10103-002-0235-5

[16] Celik, E.U., Ergücü, Z., Türkün, L.S. and Türkün, M. (2006) Shear Bond Strength of Different Adhesives to Er:YAG Laser-Prepared Dentine. Journal of Adhesive Dentistry, 8, 319-325.

[17] De Munck, J., Van Meerbeek, B., Yudhira, R., Lambrechts, P. and Vanherle, G. (2002) Micro-Tensile Bond Strength of Two Adhesives to Erbium:YAG-Lased vs. Bur-Cut Enamel and Dentine. European Journal of Oral Science, 110, 322-329. http://dx.doi.org/10.1034/j.1600-0722.2002.21281.x

[18] Papacchini, F., Goracci, C., Sadek, F.T., Monticelli, F., Garcia-Godoy, F. and Ferrari, M. (2005) Microtensile Bond Strength to Ground Enamel by Glass-Ionomers, Resin-Modified Glass-Ionomers, and Resin Composites Used as Pit and Fissure Sealants. Journal of Dentistry, 33, 459-467. http://dx.doi.org/10.1016/j.jdent.2004.11.007

[19] Yazici, A.R., Agarwal, I., Campillo-Funollet, M., Munoz-Viveros, C., Antonson, S.A., Antonson, D.E. and Mang, T. (2013) Effect of Laser Preparation on Bond Strength of a Self-Adhesive Flowable Resin. Lasers in Medical Science, 28, 343-347. http://dx.doi.org/10.1007/s10103-012-1158-4 
[20] Scaminaci Russo, D., Pierleoni, F., Buti, J., Ferrari, M. and Giachetti, L. (2014) In Vitro Comparison of Bonding Effectiveness of Different Adhesive Strategies. American Journal of Dentistry, 27, 323-329.

[21] Scaminaci Russo, D., Iuliano, V., Franchi, L., Ferrari, M. and Giachetti, L. (2013) Adhesion to Primary Dentin: Microshear Bond Strength and Scanning Electron Microscopic Observation. American Journal of Dentistry, 26, 341-346.

[22] ISO/TS 11405:2003 (2003) Dental Materials: Testing of Adhesion to Tooth Structure.

[23] De Munck, J., Mine, A., Poitevin, A., Van Ende, A. and Van Meerbeek, B. (2010) Testing Bond Strength: A Review of the Literature. Dental Materials, 26, 139-140. http://dx.doi.org/10.1016/j.dental.2009.11.109

[24] Goracci, C., Margvelashvili, M., Apicella, D., Sedda, M., Magni, E. and Ferrari, M. (2011) The Influence of Composite Mechanical Properties on Adhesive Microtensile Bond Strength to Dentin. Journal of Adhesive Dentistry, 13, 323331.

[25] Pashley, D.H., Sano, H., Ciucchi, B., Yoshiyama, M. and Carvalho, R.M. (1995) Adhesion Testing of Dentin Bonding Agents: A Review. Dental Materials, 11, 117-125. http://dx.doi.org/10.1016/0109-5641(95)80046-8

[26] Delmé, K.I., Deman, P.J., De Bruyne, M.A. and De Moor, R.J. (2006) Influence of Different Er:YAG Laser Energies and Frequencies on the Surface Morphology of Dentin and Enamel. Journal of Oral Laser Applications, 6, 43-52.

[27] Giachetti, L., Scaminaci Russo, D., Scarpelli, F. and Vitale, M. (2004) SEM Analysis of Dentin Treated with the Er:YAG Laser: A Pilot Study of the Consequences Resulting from Laser Use on Adhesion Mechanisms. Journal of Clinical Laser Medicine and Surgery, 22, 35-41. http://dx.doi.org/10.1089/104454704773660958 